\title{
On assemblages and things: fluidity, stability, causation stories
}

\section{and formation stories}

\section{Timothy Rutzou}

Independent Scholar

\section{Dave Elder-Vass}

Loughborough University

*** This is a pre-publication version of a paper accepted for publication in Sociological Theory. Please refer to the published version if citing.

* Correspondence should be addressed to Dave Elder-Vass by email at d.eldervass@lboro.ac.uk. Department of Social Sciences, Loughborough University, Ashby Road, Loughborough, LE11 3TU, United Kingdom.

Acknowledgements: Timothy Rutzou would like to thank the Templeton Foundation, and Dave Elder-Vass the Independent Social Research Foundation, for their financial support. We are grateful to the anonymous reviewers for their extremely helpful comments and suggestions. 


\title{
On assemblages and things: fluidity, stability, causation stories and formation stories
}

\begin{abstract}
This paper conducts a dialogue, and creates a new synthesis, between two of the most influential ontological discourses in the field of sociology: assemblage theory and critical realism. The former proposes a focus on difference, fluidity and process, the latter a focus on stability and structure. Drawing on and assessing the work of Deleuze, DeLanda and Bhaskar, we argue that social ontology must overcome the tendency to bifurcate between these two poles and instead develop an ontology more suited to explaining complex social phenomena by accommodating elements of both traditions. Going beyond DeLanda's recent work, we argue that a concept of causal types must be employed alongside a typology of structures to give us an ontology that can sustain sociology's need for both formation stories and causation stories. We illustrate the necessity and value of our proposed synthesis by discussing MacKenzie's recent empirical analysis of a high frequency trading firm.
\end{abstract}

Keywords: assemblage, heterogeneity, Deleuze, DeLanda, critical realism 


\section{On assemblages and things: fluidity, stability, and causation}

stories

Social ontologies are systematic accounts of what kinds of phenomena are to be found in the social world and, in relatively abstract or general terms, how they operate. One of the challenges facing any social theorising that takes ontology as its task is accounting for the inherent and irreducible heterogeneity of social objects (Little 2016). Social science necessarily deals simultaneously with agents, structures, relations, processes, and various other social dynamics. Successive theoretical positions have been inclined to resolve this problem of ontological complexity by bracketing or collapsing the heterogeneity of the social in one way or another through taking a certain element to be more basic than others; agents, structures, or relations, for example, become the fundamental quanta of social reality while other elements are redefined accordingly. Historically, this produces a pendulum swing in social theory between alternate resolutions of the problem of heterogeneity and complexity; a certain account becomes fashionable and dominant while others fall out of favor and retreat into the shadows only to be rediscovered later and rise to prominence again. As a result, the favoured elements in the ontologies secreted in social theory tend to oscillate, and in multiple dimensions: between structures and actors, objects and process, materiality and culture, relations and autonomous essences. 
This paper focuses on one of these dimensions: the tension between object-focussed and process-focussed ontologies. This is not to say that the other dimensions are unimportant: their significance is widely discussed in the literature, and indeed we have contributed to those debates ourselves (e.g. Elder-Vass, 2010, 2012, 2017; Rutzou, 2017). But the object/process divide is less frequently addressed in the mainstream sociological theory literature and yet the tension between these two poles is of fundamental importance to understanding the social world.

On the one hand, ontologies of fluidity have stressed the contingency and dynamism of the social world, typically seeing the world as composed of processes rather than objects or structures, and often neglecting the need to explain the stabilities of social reproduction (Abbott, 2016; Bennett, 2010; Coole and Frost, 2010; Deleuze and Guattari, 1983, 1988). On the other hand, structure-oriented ontologies have tended to portray the world as composed of persistent forms, definite boundaries, essences, and consistent causal capacities, at the expense of the more chaotic and dynamic aspects of the social world (Bhaskar, 1975; Bryant, 2011; Harman, 2016). This is not to say that either tradition ignores social change or cases of social stability, nor that either is incapable of explaining social change or stability. Rather, the distinction is that process-oriented ontologies tend to explain social outcomes as being produced by process and theorise structural forces as unstable products of fleeting interactions, while structure-oriented ontologies tend to explain social outcomes as being produced by relatively stabilised structures and see process as secondary. 
In response to this problem, our strategy will be to stage an encounter between what we consider to be the most developed and coherent enunciations of the process and structure approaches to social ontology - assemblage theory (DeLanda, 2006, 2016; Deleuze and Guattari, 1983, 1986, 1988) and critical realism (Archer, 1995; Bhaskar, 1975, 1979; Elder-Vass, 2010). Assemblage theory is a process oriented ontology that is driven by what we call the problematic of origins - forefronting explanations of how things come to be the way they are. Critical realism, by contrast, is a structure oriented ontology that is driven by the problematic of causal power-forefronting explanations of how things have the capacity to influence the world. By comparing, criticising, reformulating and elaborating elements of both traditions this paper seeks to construct a more open and flexible synthesis, and one that can address both of these problematics.

The productivity of such an engagement is not a novel idea. Coole and Frost (2010), Bryant (2011), DeLanda (2006, 2011, 2016), and Harman (2016) have either engaged with, or indicated their influence by, the work of Roy Bhaskar, while on the side of critical realism Elder-Vass (2008, 2015), Little (2016), Rutzou (2017), and Decoteau (2018) have also argued for the need for a productive engagement between these traditions as a means of developing more suitable ontological models for social theory. This practice of making such connections between related but in some respects conflicting schools of thought should be familiar to sociological theorists 
through examples such as Sewell's productive confrontation of the work of Giddens and Bourdieu (Sewell, 1992). Yet, despite these connections having been drawn, what has been lacking until now is a fully coherent engagement and synthesis between assemblage theory and critical realism that unfolds their points of convergence and divergence, and demonstrates the benefits that a conjunction between them might bring. Manuel DeLanda has made the largest steps towards bringing these traditions together, but we will argue that his work is hampered by a failure to embrace the realist concept of causal types. Arguing from a broadly critical realist position, but one that is open to the merits of assemblage theory, this paper advocates a synthesis between the two that combines Bhaskar's account of stratification, real causal powers and generative mechanisms, the concepts of assemblage, strata and territorialization in the work of Deleuze and Guattari, and DeLanda's notion of parameters. The result of this encounter, we believe, is an ontology better suited to accounting for the complex and dynamic processes of change and stability within social phenomena.

While the place of ontology has always been controversial in social science, perhaps the most important function of ontology for social researchers is that it directs focus towards some ways of thinking about the phenomena that they study, and away from others. As a framework for study ontology can perform both a sensitising and a regulating role, functioning akin to a guide that provides a systematic framework for avoiding improvised, implicit, incoherent, or logically irresponsible hypotheses. While ontology is often equated with a priori theorizing, this need not be the case. We argue that social ontologies can be evaluated against an empirical criterion: they should 
encompass all those phenomena identified by good empirical studies. This process may seem circular insofar as social research is influenced by ontology, and ontology is judged by the findings of social research. Our view, however, is that empirical studies can break out of this circularity when they identify phenomena that challenge their presumptive ontology, secreting either explicit or implicit challenges to the ontology that guided them in their results (Elder-Vass, 2007). An example from assemblage theory is perhaps Latour's introduction of values and institutions in his An Inquiry into the Modes of Existence (Latour, 2013), despite having dismissed social or cultural structures in his earlier work as black boxes to be eliminated by opening them (Latour, 2005). On the critical realist side we could count, from our own work, the addition of complexes of practices to explain the ontology of economic form in Profit and Gift in the Digital Economy (Elder-Vass, 2016). We can therefore judge ontologies against substantive research at the same time as we assess substantive research against ontological criteria. Where discrepancies arise, there can be no a priori presumption as to which is in error, but a discrepancy at least indicates that further work is required. Where there is harmony, both the research and the ontology are corroborated and mutually supported.

On this basis, we argue that a great deal of explanatory work in the social sciences needs an ontological framework like that proposed here, particularly given that the vast majority of social phenomena are produced in circumstances where relatively stably reproduced familiar social objects interact with far more dynamic and transient objects. It would be a vast undertaking to validate this claim by reference to the entire 
body of social research, but we aim to make a small beginning by validating our model against a single high-quality empirical study - Donald MacKenzie's recent case study concerning high-frequency stock trading (MacKenzie, 2017). Mackenzie's study reveals and depends on both types of phenomena. This provides the base from which we introduce and evaluate assemblage theory and contemporary critical realism. We then move onto questions of synthesis by exploring the work of DeLanda, presenting our own synthesis of the positions, and finally illustrating the value of our solution by returning to Mackenzie's empirical study for corroboration (MacKenzie, 2017).

One further note before beginning: both assemblage theory and critical realism are general or philosophical ontologies that aim to encompass both the natural and the social. While we will favour social examples, many arguments from both Deleuze and Guattari (hereafter D\&G) and Bhaskar are intended to apply to both. For this reason, we will use non-social examples where the original authors did so or where such examples illustrate a point more clearly, while recognizing the limitations of such examples. Furthermore, both ontologies recognise material objects as part of the 'social' world, problematizing the natural/social distinction and arguing for a fundamental unity across ontological realms (c.f. Latour, 1993).

\section{Fluidity and stability in practice}

In thinking through the problem of ontological heterogeneity, Donald MacKenzie's detailed historical account of Automated Trading Desk (ATD), a high-frequency stock 
trading firm, offers a fitting illustration of the need for new and better ontological models (MacKenzie, 2017). ATD was founded in 1989 by two partners, who employed two programmers to write software that could predict stock prices and place automated trades. Over the early years of the firm it underwent various changes, such as switching from a business model oriented to supplying services to other trading firms to becoming a trading firm itself and converting the programmers into stockholders during a period when the firm was unable to pay their wages and so compensated them in stock instead. This is not untypical; many small firms go through similar changes, modifying their form, their objectives, and in the majority of cases collapsing entirely. Here we have different and competing social structures coming into being from scratch then undergoing structural fluidity as they seek to adapt to their environment until (with luck and judgement) they are able to stabilise temporarily, at least - in a viable form. At any one point, the firm has a certain form, and may exercise causal influence arising from that form, but during the stages of its development that form is often dynamic and unstable.

This sort of case poses a challenge to ontologies that stress the endurance of objects and structures, such as critical realism. ${ }^{i}$ As Hirschman and Reed have argued, critical realists (and many other sociologists) tend to develop explanations that deal with relations between existing objects or structures, but this needs to be supplemented with "formation stories", which account for how objects get formed in the first place (Hirschman and Reed, 2014). .i As they point out, the assemblages approach is more focused upon origins - and encourages us to think of the new and evolving firm in 
much more fluid terms. This is not to say that critical realism entirely neglects origins. Margaret Archer in particular has argued that social ontology needs to incorporate history. Her concept of the morphogenetic cycle - in which actions are influenced by the structural context which in turn leads to either processes of reproduction or transformation of that context - is one type of formation story (Archer, 1995: 15461). While Archer's concept is in principle able to deal with quite discontinuous change, realist applications typically assume that a reasonably stabilised structure exists already such that it can be incrementally changed, rather than conceiving of structures that are inherently heterogeneous, fluid, unstable, or yet to exist.

If developmental processes need to be built into social ontology, as assemblage theory implies, these processes need to be understood relationally rather than linearly. It is impossible to make sense of ATD's history without recognising the enormous influence of other related structures, including the New York Stock Exchange (NYSE), which had already existed for almost 200 years when ATD was founded, and which had stabilised both as an organisation and as a set of practices regulating much of the stock trading in the US. An important part of ATD's story was the work it had to do to fit into or work around the far stabler pre-existing structure of the NYSE and its effects. That is not to say that the NYSE was completely unchanging, and in fact ATD was one of the players whose actions influenced those changes - but nor is it true that ATD itself was completely fluid, even in its early phases: there were significant elements of continuity of location, personnel, legal form and general objectives. Still, in an important sense, ATD's story is a story of interaction between 
relatively fluid and relatively stable social structures. These relatively stable structures constitute a challenge to assemblage theory, with its tendency to class all social phenomena as ephemeral and fluid in the service of accounting for their contingent history.

The formation story of ATD, in other words, depends on elements of both stability and fluidity. On the one hand, ATD's entire business was premised on the possibility of exploiting new forms of technology, which themselves changed radically over the course of MacKenzie's narrative, generating and closing down opportunities in unprecedently short periods of time. On the other, the institution of trading shares of joint stock companies on an exchange and many aspects of the legal framework for doing so (though by no means all) were relatively stable across the period of the study and it was in response to this that these new forms of technology evolved. The institutions of joint stock companies and stock trading also contribute to the widespread recurrence of such companies and indeed of stock exchanges as organisational structures, providing a context that massively increases the stability of such structures. They are also central, however, to causation stories in which the ongoing capacity of companies like ATD to trade stock is explained, as well as to the formation stories in which the development of ATD is explained.

No doubt a study of a different case would show different elements of fluidity and stability across different contexts, and no doubt the balance between the two would differ significantly from case to case. But MacKenzie's study and the ontological 
questions it raises are already more than sufficient to demonstrate that ontology must find room for thinking both fluidity and stability, and both formation and ongoing causation in order to understand the complexity of such phenomena. With this in mind, we will now turn to the alternative ontological approaches to assemblages before returning to ATD as a yardstick of these alternative approaches.

\section{Assemblage theory: Deleuze and Guattari}

While there have been many assemblage theorists, Deleuze and Guattari (D\&G) were pioneers in theorizing assemblages, as a means of rethinking ontology by focusing upon difference. Ontology is defined in their work, not by reference to static forms, hierarchies, or essences, but by multiplicities, processes, and flows. Objects, entities, properties, even Being itself is constituted by difference and heterogeneity, multiplicity, rupture, diverse and diffuse relations, linkages, mutations, processes, individuals, and becomings (Deleuze and Guattari 1987: 5f). Within this ontological context the concept of assemblage operates to challenge and critique traditional accounts of structure, totality, and causation by reconstructing an ontology around continuous variation, hybrid phenomena, dynamic change, growth, discontinuity, and contingency (c.f. Deleuze and Guattari 1987: 97-100), while providing a means to theorize and understand the relational interactions of component parts and wholes by attending to the way different things come and are held together i.e. assembled.

Writing about assemblages, let alone trying to synthesise the theory with another tradition such as critical realism, presents a number of challenges. Assemblage theory, 
particularly in the case of D\&G, explicitly attempts to avoid standard and familiar images instead attempting to structure an entirely new philosophical perspective. This intentionally leaves the reader somewhat disoriented by a proverbial assault upon their vocabulary. Although there is a consistency and coherency to the underlying thought, their writings are designed to defy summary and render systematicity near impossible (Massumi, 1996). Even the word assemblage carries within itself a fundamental ambiguity: as an attempt to translate the original French agencement it refers to both the action of fitting together a set of components, and the result of such an action (DeLanda, 2016: 9). As a consequence the word itself encompasses aspects of both process and structure with connotations that include "dispose, arrange, combine, unite, compose, constitute, ... connect, order" (extracted from a longer list in Law, 2004: 167 n. 37).

For D\&G, assemblages and other systems should not be thought of as unities, but rather as compositions, defined by difference. Assemblages are not structures but rather 'living' arrangements, unsettled and mobile by nature, rather than fixed or hierarchical. Instead of having a stable form or an essence that indicates an underlying unity or homogeneity, an assemblage is characterized by an unstable set of interior and exterior relations between parts and wholes. Assemblages are open and heterogeneous systems - diffuse networks which connect together different components into complex ensembles that resemble "rhizomes" (Deleuze and Guattari, 1988). Universities, for example, are by no means stable or even stablybounded social objects, as they morph in response to changes in the political and 
economic environment, demonstrated recently by shedding functions to private contractors that used to be considered core to their identities (Bacevic, 2018). As clusters of independent but interrelated parts, assemblages encompass the interaction between different types of social things ranging from material forms (persons, bodies, and things c.f. Deleuze and Guattari 1983), practices (action, activities, agencies c.f. Deleuze and Sacher-Masoch, 1991), knowledge (epistemes, scientific statements, concepts, discourse c.f. Deleuze 2014), social organizations (capital, culture, politics, bureaucracies, institutions and organizations c.f. Deleuze and Guattari 1983, 1988) and forms of expression (gestures, words, music, affect, desire c.f. Deleuze and Guattari 1986, 1988). An assemblage operates as the intersection and conjunction - the coalescence - of these different components; a mobile army of multiplicities characterized by varied interactions and changing liaisons. Assemblages resist all accounts that would ascribe them - or the phenomena they generate - to one true source or uniting principle (May, 1997: 177). Rather, Deleuze suggests, with his characteristic metaphorical flair: “...the assemblage's only unity is that of a cofunctioning: it is a symbiosis, a 'sympathy'. It is never filiations which are important, but alliances, alloys; these are not successions, lines of descent, but contagions, epidemics, the wind" (Deleuze and Parnet, 2002: 69).

Where concepts such as structure or systems in social science lend themselves to explanations of how social life is shaped into recurring and consistent forms, assemblages resist this logic. There is no possibility of reduction to some basic or underlying property or mechanism such as the Oedipal complex, capitalism, culture, 
or nation state which can explain (or explain away) heterogeneity by reference to an underlying unified whole. Indeed, at the heart of assemblage theory is a critique of the reductionism inherent to traditional forms of totalizing analysis from psychoanalysis to linguistics to Marxism. Taking psychoanalysis, linguistics, and Marxism as examples, each are argued to posit either a primordial and universal mechanism (the Oedipus Complex), generative structure (Chomsky's grammaticality; Levi Strauss' binaries), or internal relationship (Capitalism, worker-owner) which governs and explains the whole and forms the basis for systematic scientific thought. In contrast D\&G are quick to emphasize the inherent heterogeneity of the whole. Against Marxism, for example, D\&G paint capitalism as schizophrenic rather than homogenous (and therefore "paranoiac"), and return to, and radicalize, the language of the communist manifesto in which capitalism is described as the uninterrupted disturbance in which: "all fixed, fast-frozen relations, with their train of ancient and venerable prejudices and opinions, are swept away" and "all that is solid melts into air..." (Marx and Engels, 2000: 248). In contrast to totalizing forms of explanation the language of assemblage draws attention to the manner in which different things tend to become integrated and entangled and yet still remain decentered in their "core"; parts which are independent of each other, but which function together (for a time anyway) providing a degree of both contingency and recurrence (Deleuze and Guattari, 1986: 37). For D\&G ontology consists in a complex interplay between heterogeneity and homogeneity, dynamism and recurrence, but heterogeneity and dynamism always seem to have the upper hand. 


\section{Structure and depth in Deleuze and Guattari}

The appeal of assemblage theory lies in its emphasis upon processes and particularities. It provides ontological warrant and a conceptual framework for writing complex and non-linear formation stories, which avoid generating unifying narratives. However, it also presents a number of issues. For many commentators, the focus upon relations, change, contingency, and difference seems to go too far, to the point at which the radical project of D\&G melts everything into air (or perhaps "the wind"); the result being what appears to be an ineffable and diffuse ontology in which everything turns to smoke the moment we try to grasp hold of it (Norrie, 2009: 192212). But a closer reading of $D \& G$ also reveals elements of structure, strata, stability, and depth. In D\&G assemblages are defined along two dimensions: one horizontal and the other vertical. On the horizontal axis, entities are comprised of "a machinic assemblage of bodies, of actions and passions ... [and] collective assemblage[s] of enunciation, of acts and statements" - what we might think of as their parts (Deleuze and Guattari, 1988: 88). The second (and often neglected) dimension is a vertical axis which is concerned with the operations that stabilize and make "coherent" (territorialize), or destabilize and make "incoherent" (deterritorialize) structures, entities, and phenomena, giving rise to different forms of strata and stratification (for example codings, symbols, hierarchies, power, and genealogies). These two dimensions define the tension inherent to assemblages as wholes that exist in a state between stability and instability: stable insofar as the existence of certain forces is able to maintain the cohesion of the whole, unstable insofar as these forces are 
contingent. Indeed, it is characteristic of D\&G's work to portray things as stable and dynamic to different degrees.

Strata are viewed as levels, populated with relatively stable objects composed of parts that themselves are drawn from the populations of substrata (Deleuze and Guattari, 1988: 79-80). Because of this strata can be grouped, and they suggest three groupings: "physico-chemical, organic, and anthropomorphic" (i.e. cultural) (Deleuze and Guattari, 1988: 584), all of which are highly suggestive of the sort of level structure common in realist ontologies (Deleuze and Guattari, 1988: 66-70; ElderVass, 2010). Strata are built on substrata, employing the materials provided by the substratum, and forming them into elements and compounds as a result of the operation of abstract machines, sometimes referred to as diagrams (Deleuze, 1988: $34,39)$.

The concept of an abstract machine is somewhat obscure, but it provides a potentially instructive set of parallels with critical realism. iii Abstract machines do not exist as concrete realities that can be isolated from the form they take, but bring together diverse assemblages under a particular regime or order (May, 2005: 141). One difficulty in defining the abstract machine is situating its relation to the machine. A machine is, loosely speaking, a kind of pattern and/or driver of the possibilities that a given assemblage faces for productive interaction with other assemblages, particularly those interactions that lead to its own further development. If a machine is a pattern/driver of possibilities for a given assemblage, then an abstract machine would seem to be an equivalent pattern/driver for a wider set of assemblages. For example, 
Deleuze interprets Foucault's concept of Panopticism as a diagram or abstract machine in the sense that it is a general pattern of the use of architecture to provide optical possibilities of surveillance that can help to mould human behaviour, a pattern that is found across a wide range of institutional buildings and not just the prisons that provided the initial model for the concept (Deleuze, 1988: 34; Foucault, 1991: 205).

A more profound difficulty is the ontological status of abstract machines. They are "Abstract, singular, and creative, here and now, real yet nonconcrete, actual yet noneffectuated" (Deleuze and Guattari, 1988: 594). D\&G situate abstract machines in the virtual, a concept drawn from Bergson that refers to an ontological domain that is real without being strictly actual, but nevertheless somehow enveloped in the actual (DeLanda and Harman, 2017: 60). If we may take the actual as referring to those things and events that exist in the ordinary material sense, the "real but not actual" generally refers (in both Bhaskar and Deleuze) to features of the world that are not instantiated in actual things. DeLanda gives the example of dispositions of things that are not currently manifested, such as the power that a knife has to cut, when it isn't actually cutting anything, but this is drawn from Bhaskar's scheme, not D\&G's (DeLanda and Harman, 2017: 68) (cf Bhaskar, 1978: 252). Similarly, “Abstract machines operate within concrete assemblages" (Deleuze and Guattari, 1988: 593), and so are in a sense enfolded within actual things. Indeed, this is the only kind of existence that D\&G allow them, as "There is no abstract machine, or machines, in the sense of a Platonic idea, transcendent, universal, eternal" (Deleuze and Guattari, 
1988: 593).

Even by the standards of $D \& G$, the ontology of abstract machines and diagrams is extraordinarily obscure. They are ascribed the status of being virtual, and yet always exist as features of actual assemblages, leaving it unclear just what it means for them to be virtual. They are described sometimes merely as patterns, but at others as having causal influence: in his book on Foucault, Deleuze claims that diagrams are "continually churning up matter and functions in a way likely to create change", that they make history, and act "as a non-unifying immanent cause" but then immediately draws back to say that "the abstract machine is like the cause of the concrete assemblages that execute its relations" (Deleuze, 1988: 35-6, emphasis added). And yet is it unclear how these patterns could be causal, or if they are not, in what respect they are "like" causation. Perhaps the clearest explanation can be derived from the example they give of DNA, although some interpolation is required to fill in the gaps. An organism's DNA is made up of repeating nucleotides organised in a specific sequences or patterns. DNA provides a series of instructions that influences and restricts the development of the larger organism (formation story) and accordingly the behaviours of the resulting assemblage (causation story), both by enabling some developmental paths and excluding others. While this seems to express the force of abstract machines, the analogy is troublesome. First, it is not the pattern as such that shapes the development of the organism but the material instantiation of the pattern, the structure of DNA itself, and so it is unclear what role the pattern as such is supposed to be playing, although there is a hint that it defines the alternative 
possibilities for the assemblage (Deleuze, 1988: 37). This leaves the ontological status of these patterns extremely unclear. In what sense is there an abstract machine that is any sense ontologically distinct from the many strings of similar DNA found in a particular organism, or the many strings of somewhat less similar DNA found in multiple organisms of the same species? The consequence of this ambiguity seems to be that causation and formation stories unhelpfully blur together by placing emphasis upon patterns as a means of avoiding ontological questions. We will argue below that these issues are resolved much more satisfactorily in critical realism with its emphasis upon causal mechanisms.

\section{Critical realism}

Despite many differences in orientation, a surprisingly fruitful dialogue can be had between D\&G and critical realism (Bryant, 2011; DeLanda, 2006, 2011, 2016; Little, 2016; Rutzou, 2017). While it is tempting for realists to reject outright the outrageously heterogeneous ontology of $D \& G$ there are some important resonances between the two particularly when it comes to the emphasis on complexity and causal over-determination (Rutzou, 2017). Both philosophies are concerned with the concrete analysis of concrete situations and focus upon how diverse elements interact to produce a given outcome. Both are grounded in a rejection of causal laws. Both are concerned to avoid reductionism and emphasise the necessity of a "dialectical" and "relational" approach to social ontology. Both stake their claims on an ontology of 
open systems. Yet, centrally, CR and D\&G depart on the issue of how structures should be defined and understood.

The central gesture of CR is to assert depth structures: levels of reality that are stable and exist out of phase with the often chaotic empirical surface. Roy Bhaskar, the leading advocate of the philosophy of critical realism, articulates this differentiation and stratification by reference to an ontological distinction between levels of the empirical (experiences), the actual (which includes all events, whether they are experienced or not), and the real (which includes the actual but also causal mechanisms that are not currently instantiated in the actual) (Bhaskar, 1975: 56). Bhaskar himself is a little unclear on the relation between structures and mechanisms, so we rely here on our own developments of his work. Structures, for us, are objects (broadly construed) in the natural and social worlds with causal powers that are emergent in the sense that they are not possessed by the parts of the structure, even collectively, unless and until they are organised into a structure of this type (ElderVass, 2010: 16-23). Queues, for example, have the power to serialise access to a resource, but the people who are the parts of a queue at a given moment would not have this power if they were not organised as a queue. Objects have the powers and properties that they do by virtue of generative mechanisms, which in the simplest cases can be seen as processes of interaction between the parts of an object that produce its causal powers. Queues function because the people in them stand in order of arrival and move forward in the same order without which it would cease to be a queue and become something like a mob. This account of structure and 
mechanisms is further complicated in that structures may exist at different depths and may vary in their powers and properties accordingly. The power of queues depends on their internal structure and processes but those processes in turn depend on the participants being positioned in a larger normative system that conditions them to follow those processes (Elder-Vass, 2010: 146-8).

Perhaps the key to making sense of this ontology is the relationship between actual structures and mechanisms on the one hand, and those that Bhaskar thinks of as real but not actual on the other. Actual objects or structures exist in the ordinary sense of the word - as material things, or at least based in material substrates - and events are changes in such things so also belong in the realm of the actual. Causal powers are actualised in such objects, as a product of generative mechanisms which are actualised in interactions between their parts. Hence there is a sense in which structures, powers and mechanisms all appear within the domain that Bhaskar calls the actual. In also placing these in the non-actual element of the domain of the real Bhaskar is asserting that there is something important about generative mechanisms that is not captured in their actualisations. This can be expressed most clearly as a counterfactual: if an object was to exist that was composed of certain types of parts organised into certain types of relations with each other then its parts could interact in a certain way to generate a certain causal power. This counterfactual may be true irrespective of whether any such objects exist in the actual domain. It is real but not actual (Elder-Vass, 2010: 45-6). The argument also entails a commitment to causal types: there may be multiple actual objects that fit the counterfactual by virtue of 
possessing relevantly similar parts and relational structures, and any actual object that fits the counterfactual will have the related mechanisms and powers (Elder-Vass, 2012: 125-31).

In Bhaskar such structures critically depend on their relations and interactions; all the more so in the social world (Rutzou, 2017). Through those relations causal powers can be exercised as various structures influence, interact and interfere with one another, resulting in mechanisms being 'triggered', 'actualized', or 'realized' in different ways. In open systems, i.e. outside of the laboratory and comprising the vast majority of the world, the operation of these mechanisms cannot be understood as a closed equation of isolated events and regularities of the kind that positivist social scientists sought. Instead, they are seen as a series of constellations and conjunctions, 'impure forms' in which different structures and mechanisms interact to produce novel and emergent results (Steinmetz, 2004: 388). Because of this, different levels of structure, different mechanisms and powers can be operating concurrently without being manifest let alone empirically measurable; they may in fact only be known through their effects and in highly context-sensitive ways (Bhaskar, 1978: 252). They may sometimes produce partial regularities in the social world but these depend on the contingent reproduction of relatively similar configurations of causal forces that do not obstruct the mechanism producing the regularity. Following this, CR has emphasized that causation needs to be understood 'in the wild', i.e. in open systems which are heterogeneous and complex (Little, 2016; Steinmetz, 2004). Yet this still depends upon situating causation within a depth ontology. Indeed, the goal of the 
critical realist is to penetrate and uncover the deeper, hidden, mediated and not immediately perceptible networks of tendencies, relations and mechanisms of nature which operate behind and govern events, rather than remaining at the shallow surface of experience, appearance, and regularity. Critical realist causal explanations seek to identify actualised mechanisms and then - implicitly at least - to abstract from them to the real but not actual 'structures' that constitute their conditions of possibility and are realised in different counterfactuals.

There are echoes here of $D \& G$ 's abstract machines, not least in the sense that Bhaskar explicitly locates causal powers in the real but not actual (Bhaskar, 1978: 46, $56,119,252 n)$. Actual things, for critical realists, do have causal powers, but there is also an aspect of causal power that is real beyond any instantiation in actual things. It may be true, for example, that a certain DNA sequence (suitably located in an embryological context) would have a tendency to produce a certain sort of organism, and the truth or falsity of claims like this one is independent of whether or not such a DNA sequence actually is instantiated in an organism - or ever has been (Elder-Vass, 2010: 46). Still, despite the difference in principle, in practice the two accounts converge: the DNA sequence, for critical realists too, can only bring about these results when it is instantiated in an actual organism. We argue, however, that Bhaskar's account is more powerful. . It eliminates the ontological puzzle created by calling abstract machines virtual yet insisting they are only present in the actual, by locating generative mechanisms both in the actual, where they have actual effects, 
and in a different form in the real but not actual, where they stand as potentials of all members of a given causal type.

Critical realism's account of causation not only resembles that of assemblage theory, it provides an important corrective. CR offers a robust theory of causation that promises an explanation of both the contingency and recurrence of phenomena in the natural and social world and clarifies the relationship between actual and virtual that remains ambiguous within assemblage theory. However, the relationship between causation, diversity, and dynamism within CR remains relatively under-theorized and as a consequence expositions of CR tend to fall back on models that emphasise homogeneity. By contrast with D\&G's orientation to the biological and the social, causation is often filtered through the lens of natural science in general, and often chemistry and physics in particular. The result is that its theory and models of causation seem to place emphasis upon mechanisms requiring 'things' or 'structures' to be of consistent and stable types. This creates a degree of ambiguity as to whether the CR account of causation is committed to an ontology of essences and kinds (DeLanda, 2002; Rutzou, 2017). If we were to think of ontology as a spectrum it seems CR tends towards a structure-oriented ontology grounded in forms of unity while assemblage theory advocates for a process-oriented ontology characterized by forms of difference. 


\section{DeLanda's solution}

Although these ontologies of fluidity and stability, of formation and causation, are often seen as antithetical, there is another possibility: that each describes important aspects of reality, all of which ought to be included in a fuller ontology. Manuel DeLanda is one of the few realist assemblage theorists and recognises the need for an ontology that has room not only for the uniqueness and contingency of fleeting things and causal configurations, but also for the existence of systematic similarities between the features and causal capacities of things, some of which are persistent or stable (DeLanda and Harman, 2017: 20). His work, and particularly his recent book Assemblage Theory (2016), can at least in part be seen as an attempt to address this challenge. As a self-proclaimed realist (DeLanda, 2016: 138), who also sees Deleuze as a realist (DeLanda, 2002: 4), his orientation to these problems has a great deal in common with ours. However, there is a sense in which the "contrast space" (DeLanda, 2002: 164-5) of DeLanda's (and Deleuze's) ontology remains very different from critical realism's. While their ontologies are primarily responses to the problematic of origins - how do things come to be the way they are? - critical realism's is a response to the problematic of causal power - how can things have causal influence? - and this has a significant effect on their content as well as their orientation. One tends to produce formation stories, the other causation stories (cf Hirschman and Reed, 2014). The first part of DeLanda's solution lies in his adaptation of Deleuze's concept of assemblages. Like Deleuze (he claims) but unlike some other assemblage theorists 
such as Latour (Elder-Vass, 2015), he sees assemblages as contingent but persisting historical individuals with part-whole structures. Deleuze's assemblage theory, he argues, "was meant to apply to a wide variety of wholes constructed from heterogeneous parts. Entities ranging from atoms and molecules to biological organisms, species and ecosystems may be usefully treated as assemblages and therefore as entities that are products of historical processes" (DeLanda, 2006: 3). . On this account, assemblages are hierarchically structured entities composed of other assemblages (DeLanda, 2006: 3) - another parallel with critical realism, as we understand it (e.g. Elder-Vass, 2010: 19).

Unlike Deleuze, but like critical realists, DeLanda also invokes the concept of emergence to explain the properties of assemblages (DeLanda and Harman, 2017: 23). Emergent properties are "the properties of a whole caused by the interactions between its parts" and if a whole has such properties they cannot be reduced to properties of the parts (DeLanda, 2016: 9). ${ }^{\text {iv }}$ Such properties depend on the properties of the parts, but they can also act back on the parts (DeLanda, 2016: 71). Given that assemblages are composed of other smaller assemblages and that this is a recursive or nested structure, this means that properties emerge at many different levels (DeLanda, 2002: 171).

For many Deleuzeans, and even in Deleuze himself, emphasis is placed on the inherently fluid and transient aspects of assemblages. But, as we have seen, Deleuze also makes space in his ontology for strata - which DeLanda interprets as more stable 
substances or structures that form the environment in which assemblages develop and operate (DeLanda, 2016: 8, 23). DeLanda, however, argues in Assemblage Theory for "a different version of the concept of assemblage, a concept with knobs that can be set to different values to yield either strata or assemblages (in the original sense)" (DeLanda, 2016: 3). DeLanda's assemblages, in other words, can be ranged across a continuum, in which the more stable things that Deleuze calls strata form one end of a scale and the most transient and unstable assemblages the other (although the continuum is perhaps multi-dimensional). ${ }^{v}$

The position of an assemblage in a range like this, by comparison with other assemblages, can be (vaguely) ordered, and this ordering is described by what DeLanda calls a parameter. In common usage, a parameter is a variable (usually quantitative) that describes or specifies a characteristic or state of a system. D\&G gesture towards this idea with the concept of coefficients but devote no more than a few sentences to the concept, which DeLanda has developed much further (Deleuze and Guattari, 1988: 595). For the sake of illustrating the concept, imagine that we have a scale from 0 to 10 , where a higher value corresponds to a more permanent assemblage. We might assign a parameter value of 3 to ATD in its early stages, or a mob in front of a parliament building, and a parameter value of 7 to the New York Stock Exchange or the parliament building itself. These numeric values are arbitrary, but they correspond to a real feature: ATD really is less permanent than the NYSE, and a mob really is more transient than a queue or a building. While DeLanda uses the concept of parameter in a variety of ways, the core version is of different individual 
assemblages forming a population in which differences between individuals correspond to different parameter settings (DeLanda, 2016: 56-7).

In principle there may be many different parameters, but DeLanda picks out two in particular, drawn from D\&G's work. The first is the degree of territorialization ${ }^{\text {vi }}$ or deterritorialization of the assemblage. Territorializing processes "stabilize the identity of an assemblage, by increasing its degree of internal homogeneity or the degree of sharpness of its boundaries" (DeLanda, 2006: 12) and may include processes in which "an assemblage homogenises its own components" (DeLanda, 2016: 22). The second is coding, which "refers to the role played by special expressive components in an assemblage in fixing the identity of a whole" (DeLanda, 2016: 22) - and here he gives language and chromosomes as examples. A community, for example, may be territorialized by developing normative conformity amongst its members and a hostile attitude to outsiders, and this could be supported by linguistic coding processes (DeLanda, 2016: 22). Both territorialization and coding are what we propose to call regulatory processes or mechanisms, meaning that they tend to stabilize assemblages in particular forms and thus to explain their persistence over time. An assemblage with high values of the territorialization and coding parameters would therefore tend to be a more stable and persistent entity.

DeLanda's parameters, then, provide a way of making sense of both relatively stable or persistent entities and relatively unstable or fluid assemblages within a single ontology. But he also seeks to address the possibility of recurrence of similar entities. 
Here he makes use of the concepts of multiplicity and diagram from D\&G's work, and the concept of attractors from complexity theory which he connects to Deleuze's use of the concept of singularities (DeLanda, 2002: 14, 179). For DeLanda, a multiplicity, also referred to as a diagram, is "the structure of a possibility space" (DeLanda, 2016: 122) - we may think of it, perhaps, as a field of possible assemblages with related structures (there is thus some doubt as to whether he uses diagram to mean abstract machine, as Deleuze sometimes does). It is not, however, an actual set of historically individuated assemblages. Multiplicities, like abstract machines, are virtual (Roffe, 2010). Deleuze tells us that "The reality of the virtual is structure" (Deleuze, 2014: 272) and DeLanda reads this to mean that each point in the possibility space is a different possible structure for an assemblage. Any actual assemblage represents an actualisation or individuation of a point within a multiplicity, but many other points in it may remain unindividuated. Notional points that fall outside all multiplicities, by contrast, could never be individuated.

DeLanda, like Deleuze as he understands him, vii refuses to allow types of assemblage into his ontology, and as a consequence seeks to minimise talk of resemblances between different assemblages (DeLanda, 2002: 38). Nevertheless he acknowledges that resemblances may occur, though this always "depends on contingent historical details of the process of individuation" (DeLanda, 2002: 39). The concept of multiplicity positions recurrence and resemblance as what occurs when two or more assemblages individuate the same or nearby points in the same multiplicity (or perhaps in distinct but congruent multiplicities). So far, this appears to leave 
recurrence and resemblance as nothing more than unlikely historical accidents, but DeLanda also invokes the concept of attractors: an attractor is a point in a possibility space that states tend to converge on (DeLanda, 2016: 142). If an attractor, or multiple attractors, exists in a possibility space then historical processes of individuation will have a tendency to produce assemblages that take the corresponding form, and we therefore also have a way of making sense of systematic recurrence of similar assemblages.

\section{Evaluating DeLanda's solution}

We may take DeLanda's work, and in particular his concepts of parameter, multiplicity and attractor, as a potential solution to the problem posed in this paper: the need for an ontology that can encompass both transience and stability, both difference and recurrence. As such it has both strengths and weaknesses.

Its first strength is simply that DeLanda recognises the need for such an ontology, by contrast with thinkers in the assemblage theory tradition like Latour and his fellow actor-network theorists, who treat stability as an unusual, temporary and somewhat unimportant achievement in a world "filled with currents, eddies, flows, vortices, unpredictable changes, storms, and with moments of lull and calm and recurrence" (Law, 2004: 7). Like critical realists, DeLanda is a realist about persistent entities with continuing capacities that emerge from relatively stable features of their structures. 
Yet DeLanda is also a realist about less stable and less patterned assemblages and provides us with an ontology that recognises both kinds of structure.

Its second strength is that while recognising both stability and fluidity, he avoids a dualistic solution that seeks to divide the world into two distinct stable and fluid sectors. Some assemblages are more stable than others, but he explicitly rejects the move of seeing all assemblages as irretrievably transient and all the members of some other class - strata, perhaps - as persistent and structured. Instead, his continuum clearly gels with our experience of the world. Queues are more transient than market stalls, which are more transient than nation states, for example. By placing all things or assemblages on a scale, the concept of parameters provides a route into seeing the distinction between stability and transience as itself a fluid and graduated relation rather than a binary one.

A third strength is that the concept of parameters provides a relatively accessible way of describing this relation. It's easy to imagine assemblages as a class of objects, for example, that differ in their degree of transience - so 'degree of transience' could be used as a parameter on the concept of assemblage, which allows us to apply the concept equally to queues, market stalls and states while still recognising other differences between them.

On the other hand, as we will argue below, there are also significant weaknesses in DeLanda's approach. From a critical realist perspective, the most striking is his uncompromising rejection of the need for types, classes, or kinds in a realist ontology 
(DeLanda, 2002: 38). This creates substantial problems. As we have seen, while he accepts that there are resemblances between different assemblages, he argues "resemblances and identities must be treated as mere results of deeper physical processes, and not as fundamental categories on which to base an ontology" (DeLanda, 2002: 38-9). This is symptomatic of the orientation of his work to the problematic of origins, and the corresponding contrast space: both Deleuze and DeLanda contrast their work, in particular, with a genetic notion of essences as productive of the forms of things (DeLanda, 2002: 6). They are of course right that types cannot generate instances of the type, but this does not entail that we do not need types for other purposes in a realist ontology. As Harman has pointed out in discussing DeLanda's work, it is not clear "why priority needs to be given to genetic process over fully formed individuals" (Harman, 2008: 373). Genetic processes and formation stories are important, but ontology is also concerned with the properties/capacities that objects have once they have been formed: questions that are highlighted in the problematic of causal power and causation stories. These divergent problematics are a significant driver of the tendency of the field to bifurcate into structure-oriented or process-oriented ontologies.

The challenge is that we need an ontology that is responsive to both of these problematics, and this requires us to recognise that individuals, for all their uniqueness, can also be instances of a type. DeLanda insists that "all assemblages should be considered unique historical entities, singular in their individuality, not as particular members of a general category" (DeLanda, 2016: 6). But this is a false 
opposition: unique historical entities can also be members of a general category each of us, for example, is both a unique individual and a person. Each of us has idiosyncratic properties, characteristics, and dynamics, but also characteristics that we share with other people more generally. Recognizing this tension is important as we need to recognise the existence of certain general categories if we are to be able to make sense of causality. As Bhaskar argued, we could not make sense of experimental science if the causal powers revealed by entities in the laboratory were not also shared by other entities of the same type outside the laboratory (Bhaskar, 1975: 13, $33,50)$. Nor would the mass manufacturing of technological products make any sense if we could not rely on each well-made instance of a product to behave like all the others. What we need is less a grand rejection of general categories, and more a means to theorize generalities while recognizing that they are realised in idiosyncratic forms.

For a fuller example, consider a case discussed by Latour in which a group of scientists concluded that a tropical forest is able to advance into the adjacent grassland because the earthworms in the forest soil are transporting the nutrient-rich soil of the forest into the sandy substrate of the grassland via their faeces (1999: 2). While every earthworm is at some level unique, the entire argument rests on the assumption that earthworms share a number of structural features and hence they are all able to burrow in the earth, to consume organic material, to process it in "their particularly voracious digestive tracts" (Latour, 1999: 66) and to excrete it at a different location. In DeLanda's terms, we might say that all of these earthworms individuate similar 
points in a multiplicity - in a sense the multiplicity is his equivalent to a causal type. This, however, leaves out some of the most important characteristics of causal types: that they occur when individuals share a specific aspect of structure that leads them to share certain emergent causal powers, that this helps to make it possible for us to recognise, explain and exploit such powers, and that doing so requires that we identify the specific shared structural features and mechanisms that confer similar powers on entities that are instances of the type. ${ }^{\text {viii }}$ Both abstract machines and multiplicities seem to be developed to honour assemblage theory's insistence, driven by its orientation to the problematic of origins, on rejecting categories of any sort - while in practice reinstating something vaguely equivalent (but less clear and less coherent) through the back door. Like Harman, what we "would most miss in a DeLandian universe is an adequate theory of causal relations" (Harman, 2008: 381-2).

What is missing when we exclude causal types is the transposability. ${ }^{\text {ix }}$ of causal explanation, upon which most if not all explanation rests. Without types, the finding that one earthworm moves soil cannot be applied to other earthworms to generate macro explanations of earthworms' effects on subsoil; without types the finding that a rising stock price attracts one investor cannot be applied to other investors or other stocks. Without types, the causal explanation of every event would have to be developed from scratch, as we would be unable to import causal explanations developed in other cases to help with the current explanation. Regardless of their official ontology, in practice all causal explanations draw on types in this way. 
Our other considerations relate to some of the ways in which DeLanda employs the concept of parameters, and the specific parameters on which he focuses. The ontological status of parameters is not as clear in DeLanda's book at it might be. In discussing the example of an animal (as an assemblage), DeLanda suggests that temperature could be "a parameter quantifying the temperature of the animal's environment" (DeLanda, 2016: 56). If it is reasonable to generalise from this case, then two conclusions would seem to follow. The first is that that his parameters are descriptive of individual assemblages rather than of types or classes of assemblage, since the temperature parameter can take different values for different animals on different occasions. The second is that parameters relate to actual external causal influences that affect the assemblage concerned, and thus elements in each assemblage's causal history. While the first of these conclusions is fully consistent with the broader orientation of his ontology, the second is more surprising. We would expect parameters to describe structural characteristics of the assemblage rather than external causal influences, and DeLanda's broader work recognises that such characteristics are significant, so perhaps the most plausible conclusion is that DeLanda intends both.

The first conclusion seems to limit the usefulness of the parameter concept by ruling out the possibility that types of assemblage could also have parameters: queues in general, for example, might be considered less territorialized and/or less coded than states, just as digital economies might currently be considered less regulated than more traditional economies. The conclusion that parameters refer only to external 
causal factors would also be problematic, in that it ascribes difference to differing external influence (reflecting the problematic of origins) at the expense of seeing it also as a matter of differing internal structure (reflecting the problematic of causal power). From the perspective of understanding the causal capacities of objects, including social objects, we need to recognise that those capacities depend synchronically on the actual structure of the object and only indirectly on the diachronic causal history that brought that structure about (cf Harman, 2008: 373). Indeed objects that share the same structure can share the same causal capacities even if they have quite different causal histories. Hence variation in structure can be more significant than variation in causal history when we are examining similarities and differences in the causal capacities of objects.

Finally, we need to put the specific parameters that DeLanda discusses in a wider perspective. Although in the example above he discusses temperature as a parameter, much more of his discussion focuses on territorialization and coding. We would like to see further discussion of their generality, their specific form, and on whether there are other more general and/or more specific parameters that the scheme might benefit from. Coding, in particular, seems to be of limited generality. Language clearly does play a role in stabilising and structuring many, most, or perhaps even all social entities, but not in stabilising or structuring non-social entities - such as clouds, birds, rivers and hydrogen atoms. Chromosomes, of course, do play a role in stabilising and structuring birds, but it is hard to see why we should consider them "expressive components" (DeLanda, 2016: 22) - this framing anthropomorphises a very different 
kind of mechanism. It might make more sense to separate these two and to define "the extent to which a structure is stabilised by language" and "the extent to which a structure is stabilised by chromosomes" as two different parameters - but ultimately this strategy would produce a huge number of different parameters. At this point the logic of parameterisation seems less useful than the logic of regulatory mechanisms: mechanisms that tend to stabilise structures/assemblages.

Some assemblages are stabilised, for example, by linguistically coded sets of norms, while others are stabilised by molecular bonds, others by nuts and bolts, and so on ad infinitum. What would it mean to say that there is a parameter for every assemblage that expresses 'the extent to which it is held together by nuts and bolts', another that expresses 'the extent to which it is held together by linguistically coded norms', and so on? It is not generally a matter of degree whether a particular type of assemblage is held together by a particular mechanism, and most of these parameters could therefore only take the value 1 or 0 . We therefore find it more useful to say that there are many different mechanisms involved in stabilising assemblages, and different assemblages are stabilised by different sets of mechanisms. 


\section{Towards a synthesis}

We propose that a version of DeLanda's concept of parameters can be repositioned in an ontological framework that draws more heavily on critical realism but combines it with insights from DeLanda and Deleuze, and that doing so will provide us with an ontology that is better able to accommodate both transience and stability, heterogeneity and homogeneity, difference and recurrence, and allows us to generate richer causation stories alongside formation stories.

It helps to begin by distinguishing different types of assemblage, summarised in Table 1. First, the term is sometimes used (notably by actor-network theorists) to refer to unique configurations of forces that come together to produce a given event. Let us call this a conjunctural assemblage. There is a fairly close analogue of this concept in critical realism, in which such configurations are invoked to explain actual causation: any given event is taken to be caused by a highly contingent configuration of interacting causal powers. Second, according to DeLanda, Deleuze uses the term primarily to refer to transient and unstable wholes which differ from conjunctural assemblages by being distinct from their environments. Let us call these ephemeral assemblages. This is the area that critical realism has notably tended to neglect or even dismiss. Third, DeLanda also uses the term to refer to relatively stable wholes that may have a tendency to recur in similar forms. Let us call these persistent assemblages. These correspond roughly to Deleuze's strata and to critical realism's entities or things. 
Table 1 about here.

Critical realism focuses on the first and third of these and has tended to assume that they can be sharply distinguished from each other. Assemblage theory before DeLanda tended to employ some mix of the first two, whereas DeLanda opens up the possibility of synthesis by adding the third into the mix. A productive synthesis depends, however, on the recognition that these three tend to shade into each other in practice - that many cases fall ambiguously between them by mixing elements of more than one at the same time. DeLanda's parameters accommodate the shading between ephemeral and persistent assemblages. ${ }^{x}$

While assemblage theory has paid considerable attention to the problem of how ephemeral assemblages come to be what they are, even if only transiently, it has paid less attention to the problems of why some forms of persistent assemblage tend to recur. DeLanda's concepts of parameters and attractors mark an important step forward here, but to make further progress we need to attend to the part played by specific regulatory mechanisms in stabilising assemblages. While the concept of a parameter is useful as a way of describing partial regularities at the level of structures, an explanatory social science needs to look beneath these patterns and examine how they are produced. For a critical realist, this means that we need to examine the 
regulatory mechanisms that produce or stabilise the structures (as well as the generative mechanisms that produce their causal powers, which tend to be neglected in assemblage theory).

Such mechanisms, as we have seen, are highly varied, yet certain types of components are more easily stabilised by certain types of mechanisms and yield certain types of wholes as a consequence. Nuts and bolts cannot stabilise atoms into molecular wholes, but they can stabilise bicycle wheels and frames into bicycles. Once assembled, bicycles tend to have certain causal capacities that flow from the form in which their parts have been assembled and the resulting generative mechanisms. Likewise, recruitment and training mechanisms are able to manage a turnover of individuals within organizations to sustain their structure. These regulatory mechanisms stabilise structures that in turn have generative mechanisms producing causal powers, for example imbuing certain individuals with capacities that depend on their position within the structure (such as the capacity to hire and fire). While these mechanisms will be idiosyncratic in some respects, the same or analogous mechanisms can be found operating across different contexts, creating similar effects, and forming the bases for the identification of typical features.

We need, in other words, to add types to DeLanda's ontology: to recognise that some things are instances of more abstract types and that they may therefore also have particular causal capacities that are characteristic of instances of the type. Thinkers in the assemblage theory tradition have often been extremely wary of the concept of 
type, but we believe that this wariness derives in part from having too crude a concept of type resulting from an understandable reaction to the historical abuse of the term. We advocate what may be thought of as loose types, characterised by three features: (a) An entity is not completely defined by being an instance of a type, so that individuals remain unique. All trade unions, for example, are different from each other but this does not prevent them from being instances of the type trade union. (b) Type boundaries may be fuzzy, so that individuals may be positioned ambiguously with respect to them. Is a bicycle still a bicycle, for example, when it has a stabiliser wheel added to it? How far must it change to become a tricycle? Is a bureaucracy still a bureaucracy if it adopts a flat organisation while serving a similar function as a more traditional hierarchical model? (c) Because of (a), objects can be members of multiple different types, both nested and crosscutting. A soccer club will also be a sports club (a nested type) and may also be a public limited company (a crosscutting type) and have features of each. ${ }^{\mathrm{xi}}$

We can still, however, abstract further. DeLanda's use of the concept of attractors represents an attempt to do so. An attractor is a state that other relevantly similar states tend to converge towards. DeLanda makes use of the concept in his own account of how persistent assemblages come to be stabilised - the basic idea is that some assemblages of parts tend to converge on a particular configuration and these tendencies therefore stabilise the assemblage in the configuration concerned. The concept of attractor, however, is a descriptive concept that may be mistaken for an explanatory concept. Attractors are features of possibility spaces, which are 
descriptive of what outcomes would occur in what circumstances, and directions of movement between different circumstances/outcomes, but say nothing about how those outcomes or directions of movement are produced, as DeLanda partially acknowledges (DeLanda, 2002: 178-9) . We therefore prefer to say that assemblages in a particular structural range have a tendency to persist and recur (TPAR). Such a tendency is always the product of regulatory mechanisms, and as we have seen these mechanisms vary depending on the type of assemblage, and may be offset to varying degrees by deregulatory mechanisms (Elder-Vass, 2010: 33-8). Nevertheless, the TPAR summarises the strength of such mechanisms for any given type of assemblage, and thus we see it as a parameter in DeLanda's sense. Because of its generality we see it as a more useful parameter than those which describe the strength (or presence/absence) of a specific mechanism.

While the TPAR of an individual assemblage is significant, the concept also has a more general application. If there is a tendency for parts of a certain type to stabilise in a particular configuration, this will not only tend to stabilise an individual assemblage but also tend to produce recurrence of similar assemblages. These regulatory forces, then, explain not only the existence of persistent assemblages, but also the tendency for types of assemblage to be recurrently and/or regularly instantiated by different individuals. We should stress, again, however, that these regulatory forces may be different from, or at most a subset of, the generative mechanisms that produce the causal powers of an assemblage. The former contribute to the causal history of an 
assemblage whereas the latter are the structural basis of its capacity at any one time to influence the world.

Finally, let us make clear the implication of labelling this as a tendency. In critical realism causal powers are thought of as tendencies - rather than law-like - because their realisation is always contingent, and in particular is conditional on the circumstances of any particular event. Consider the traditional nuclear family, consisting of a male and female parent and one or more children brought up by them. This has been a fairly stable and recurrent form in many social contexts over the last few hundred years, and we might therefore consider it to have a high TPAR. Yet historically there have been other social contexts where extended families were the norm and nuclear families were not, and recent developments have raised the TPAR of nuclear families with same sex parents. Clearly stabilisation of family forms depends both on the internal structure of such families and also on the wider social/cultural context. This perhaps leads us back in the direction of something like DeLanda's distinction between territorialization and coding, reframed as internal and external influences on the stabilisation of a form.

\section{Discussion}

With this in mind, it is useful to distinguish between two kinds of ontological fluidity/stability, one relating to conjunctures - the sets of causal forces that are present or influential on particular occasions - and one relating to structures - the 
forms of distinct identifiable objects or things. Any plausible ontology must recognise both fluidity and stability of both conjunctures and structures. Table 2 summarises how all four combinations appear in the ontologies discussed in this paper.

Table 2 about here.

The scope for productive synthesis arises from the shaded boxes in the table: critical realism has conceptual tools for dealing with stabilisation and causation that Deleuzians lack, while DeLanda and Deleuze provide a means for thinking about structural fluidity that goes beyond CR's rather structured approach.

We can illustrate some of the messages of this paper by returning to MacKenzie's empirical study of Automated Trading Desk (ATD) (MacKenzie, 2017). (The illustration is summarised in Table 3.) As we argued earlier, the early history of ATD - a firm in motion, repeatedly transforming itself radically until it found a successful niche demonstrates the need for an ontology that can accommodate structural fluidity. Drawing on DeLanda's approach, we could see this as a case of an assemblage converging on an attractor - a locally stable form. Once the firm takes form and starts to adapt under the influence of its founders' agency it fits Archer's Morphogenetic Model (Archer 1995), ,ii however in the earliest phases when it is still in the process of 
formation this is a less natural fit. In contrast, the assemblages approach allows us to theorise the evolving situation more clearly as new structures come into being.

On the other hand, Mackenzie's story also includes clear cases of long term structural stability, notably the New York Stock Exchange (NYSE), whose existence and practices played a major role in the developments he describes - not only in terms of the formation stories of ATD but also in terms of the causation stories to be told; causal explanations of stock trading, for example. Neither the NYSE nor ATD, however, are pure examples of stability or fluidity; even within the confines of MacKenzie's case, incremental change was occurring in the NYSE, and through most periods of the narrative there were also significant elements of continuity in ATD. As we stressed earlier, ATD's story is the story of interaction between relatively fluid and relatively stable social structures having features of each in combination.

In the terms we have proposed here, ATD had a relatively low TPAR, though one that increased as it approached a more viable business model, whereas the NYSE had a much higher TPAR - and it is hard to see how an institution like the NYSE could be accommodated in an ontology of pure fluidity, such as is found in some readings of Deleuze.

Table 3 about here. 
Furthermore, as we pointed out earlier, this is also a story of both stability and fluidity in the conjunctural context. On the side of fluidity, the technologies available to be enrolled in trading systems changed unprecedently rapidly during this period. On the side of stability, the practice of stock trading and its broader institutional framework were relatively stable and from a structural perspective it was in response to this that these new forms of technology evolved. The persistence of these institutions also enabled profuse recurrence of the objects they supported: stocks, public joint-stock companies, and stock exchanges, and tended to stabilise their forms in turn.

No explanation of stock trading would be complete that did not recognise that these stocks and companies themselves are instances of types with common causal properties. Let us consider stocks or shares. ${ }^{\text {xiii }}$ A share is a socially constructed, institutionally secured tradable financial instrument that generally entitles the holder to claim a share of the distributed profits of the corresponding firm and to vote in its general meetings. Firms like ATD trade in the shares of public limited companies, which have the added feature of being freely tradable on public stock exchanges. Many thousands of public firms have issued shares and each of them may have issued many thousands or indeed millions of shares, but for ATD, all that really matters about shares is that they can be traded on a public exchange. Shares are therefore a causal type: they all have certain properties in common that enable a company like ATD to trade them through a standardised computer system. Those systems rely on the fact that, in certain respects, all shares behave in just the same way. Stock trading as it is conducted by ATD would in our view be incomprehensible if we were to adhere to 
DeLanda's failure to recognise causal types. DeLanda might argue that it is the institution of stock trading that accords shares their similar causal powers, but we argue that this still entails recognizing shares as a causal type. Of course, the ontology of social objects like shares is more complex than that of relatively simply material objects like earthworms. The causal powers of earthworms are a product of their material composition and structure, and mechanisms that rely on these. By contrast, the causal powers of shares depend on their social positioning, as Lawson has argued for the parallel case of money (Lawson, 2016). Bhaskar puts the point more abstractly, using the concept of intrastructuration (Bhaskar, 1993: 49; Elder-Vass, 2010: 26-8): the case where causal powers produced by a higher structure are effectuated by or in effect delegated to subsidiary parts of the structure . But the fact that the powers of shares are devolved from higher level structures does not alter the fact that they all share similar powers which are the product of the same mechanism, which depends upon their sharing the same material prerequisites and the structural position that builds institutional properties on these "brute facts" (Searle, 1995). This makes them all members of the same causal type, as we understand the term.

We argue, then, that Mackenzie's study provides support, not only for the general need for an ontology that can accommodate both fluidity and stability and both formation stories and causation stories, but also for our proposed synthesis as an improvement upon Deleuze, Latour, DeLanda and earlier formulations of critical realism. The key to arriving at such a synthesis is to avoid metaphysical dogmatism not only about the degree of stabilisation of entities and conjunctures in general but also 
about the degree of homogenisation of entities. Instead it requires recognising that these are ontological issues that need to be resolved empirically rather than a priori and any ontology must be able to accommodate this. The role of the ontologist here is to accept that both more and less stable and/or homogeneous forms can be real and to provide the conceptual tools to allow both to be theorised, often within one and the same empirical explanation.

\section{Conclusion}

Good social research requires a social ontology that is both internally coherent and consistent with our experience of the world, including the evidence revealed by research. Just as many ontologists take a relaxed attitude to empirical research allowing them to cherry pick illustrations in service of the theory, many researchers take a relaxed attitude to ontology, allowing them to cherry pick concepts from different traditions. But where ontology is merely implicit, it risks inadvertent incoherence and logical irresponsibility. Where it is explicit let alone dogmatic, it risks discouraging or excluding attention to important aspects of social reality - as, for example, does Latour's explicit marginalisation, verging on exclusion, of discussion of social structure (Elder-Vass, 2008; Latour, 2005). Our focus in this paper has been on the exclusions or marginalisations lurking in the assemblage theory and critical realist traditions of social ontology, and how we might resolve them.

Those exclusions, we suggest, are at least in part a product of the different problematics to which the two traditions have been addressed: the assemblage theory 
tradition can be seen as a response to the problematic of origins - how do things come to be the way they are? - while critical realism is a response to the problematic of causal power - how can things have causal influence? The former problematic directs attention to cases of phenomena not-yet-formed and in the process of formation, and thus invites an ontology of fluidity. The latter directs attention to cases in which already-existing objects interact with each other, and thus invites an ontology of stability.

A full ontology must address both of these problematics, and there are signs of recognition in both traditions of their respective absences. The notions of strata, attractors and abstract machines at least recognise - but fail to resolve - the characteristic absences of D\&G's assemblage theory: its relative neglect of stable and recurrent structures, and its failure to recognise causal types. Archer's morphogenetic cycle provides critical realism with a means to analyse structural change, yet it does not resolve the lack of attention to unique, heterogeneous and highly unstable objects in critical realism.

An adequate social ontology must find solutions to both of these absences, and like DeLanda we believe that the Deleuzean tradition and the realist tradition can be synthesised productively to deliver such an ontology. DeLanda's move, however, opens an important conversation rather than concluding it with a completely adequate solution. This paper offers two main improvements. First, it argues that the concept of parameter should be reshaped to reflect the core issue as we understand 
it: the graduated distinction between entities with strong stabilising forces and those with weaker ones. Second, we argue, contrary to DeLanda, that social ontology requires a notion of causal types, for two important reasons: first, many entities do fall into types with similar causal properties arising from their similar structures, and many phenomena cannot be adequately explained without recognising this, but also second and more fundamentally, causal explanation in general rests upon the transposability of explanation between cases in which similar causes operate, and that this transposability depends upon the presence in those cases of objects with similar powers arising from similarities in their composition and structure. Accordingly, formation stories are necessarily interwoven with causation stories.

As our reading of Mackenzie's study of high frequency trading suggests, explanatory social science needs such an ontology: social phenomena are often, usually, or perhaps always the product of interactions between relatively stable objects that fall into consistent causal types and other far more heterogeneous, unstable, and sometimes ephemeral objects. Adopting such an ontology, we suggest, provides the basis for causation stories in conjunction with formation stories. If this paper encourages those influenced by assemblage theory to pay attention to the stable forces as well as the unstable, those influenced by critical realism to take account of the ephemeral as well as the established, and sociologists in general to attend to the potentials of both relatively stable and relatively dynamic causal forces it will have achieved our objective. 


\section{References}

Abbott A (2016) Processual Sociology. Chicago: University of Chicago Press.

Archer MS (1995) Realist Social Theory: The Morphogenetic Approach. Cambridge: Cambridge UP.

Bacevic J (2018) With or without U? Assemblage theory and (de)territorialising the university. Globalisation, Societies and Education Online ahead of print(0): 114. DOI: $10.1080 / 14767724.2018 .1498323$.

Bennett RJ (2010) Vibrant Matter: A Political Ecology of Things. Durham: Duke UP.

Bhaskar R (1975) A Realist Theory of Science. 1st ed. Leeds: Leeds Books.

Bhaskar R (1978) A Realist Theory of Science. 2nd ed. Hassocks: Harvester Press.

Bhaskar R (1979) The Possibility of Naturalism. Brighton: Harvester.

Bhaskar R (1993) Dialectic: The Pulse of Freedom. London: Verso.

Bryant LR (2011) The Democracy of Objects. Ann Arbor, MI: University of Michigan.

Coole D and Frost S (2010) Introducing the New Materialisms. In: New Materialisms. Durham, NC: Duke UP.

Decoteau CL (2018) Conjunctures and Assemblages: Approaches to Multicausal Explanation in the Human Sciences. In: Critical Realism, History, and Philosophy in the Social Sciences. Political Power and Social Theory 34. Emerald Publishing Limited, pp. 89-118. DOI: 10.1108/S0198871920180000034005.

DeLanda M (2002) Intensive Science and Virtual Philosophy. London: Continuum.

DeLanda M (2006) A New Philosophy of Society: Assemblage Theory and Social Complexity. London; New York: Continuum.

DeLanda M (2011) Emergence, Causality and Realism. In: Bryant L, Srnicek N, and Harman G (eds) The Speculative Turn: Continental Materialism and Realism. Melbourne: re.press, pp. 381-392.

DeLanda M (2016) Assemblage Theory. Edinburgh: Edinburgh UP. 
DeLanda M and Harman G (2017) The Rise of Realism. Cambridge, UK: Polity Press.

Deleuze G (1988) Foucault. Minneapolis: University Of Minnesota Press.

Deleuze G (2014) Difference and Repetition. 2nd Revised edition. Bloomsbury Academic.

Deleuze G and Guattari F (1983) Anti-Oedipus: Capitalism and Schizophrenia Volume 1. New York: Viking Press.

Deleuze G and Guattari F (1986) Kafka Toward a Minor Literature. Minneapolis: University Of Minnesota Press.

Deleuze G and Guattari F (1988) A Thousand Plateaus: Capitalism and Schizophrenia Volume 2. London: Continuum.

Deleuze G and Parnet C (2002) Dialogues II. 2nd edition. New York: Columbia University Press.

Deleuze G and Sacher-Masoch L von (1991) Masochism: Coldness and Cruelty \& Venus in Furs. Cambridge, MA: MIT Press.

Elder-Vass D (2007) A method for social ontology. Journal of Critical Realism 6(2): 226-249.

Elder-Vass D (2008) Searching for realism, structure and agency in actor network theory. British Journal of Sociology 59(3): 455-73.

Elder-Vass D (2010) The Causal Power of Social Structures. Cambridge: Cambridge UP.

Elder-Vass D (2012) The Reality of Social Construction. Cambridge: Cambridge UP.

Elder-Vass D (2015) Disassembling Actor-Network Theory. Philosophy of the Social Sciences 45(1): 100-121.

Elder-Vass D (2016) Profit and Gift in the Digital Economy. Cambridge: Cambridge UP.

Elder-Vass D (2017) Material parts in social structures. Journal of Social Ontology 3(1): 89-105.

Foucault M (1991) Discipline and Punish. London: Penguin.

Harman G (2008) DeLanda's ontology: assemblage and realism. Continental Philosophy Review 41(3): 367-383. DOI: 10.1007/s11007-008-9084-7. 
Harman G (2016) Immaterialism: Objects and Social Theory. Malden, MA: Polity Press.

Hirschman D and Reed IA (2014) Formation Stories and Causality in Sociology. Sociological Theory 32(4): 259-282. DOI: 10.1177/0735275114558632.

Latour B (1993) We Have Never Been Modern. Cambridge, MA: Harvard UP.

Latour B (1999) Pandora's Hope. Cambridge, MA: Harvard UP.

Latour B (2005) Reassembling the Social. Oxford: Oxford University Press.

Latour B (2013) An Inquiry into Modes of Existence. Cambridge MA: Harvard UP.

Law J (2004) After Method: Mess in Social Science Research. London: Routledge.

Lawson T (2016) Social positioning and the nature of money. Cambridge Journal of Economics 40(4): 961-996. DOI: 10.1093/cje/bew006.

Little D (2016) New Directions in the Philosophy of Social Science. Lanham: Rowman \& Littlefield.

MacKenzie D (2017) A material political economy: Automated Trading Desk and price prediction in high-frequency trading. Social Studies of Science 47(2): 172-194. DOI: $10.1177 / 0306312716676900$.

Marx K and Engels F (2000) The Communist Manifesto. In: McLellan D (ed.) Karl Marx: Selected Writings. Oxford: Oxford UP, pp. 245-272.

Massumi B (1996) Becoming-Deleuzian. Environment and Planning D: Society and Space 14(4): 395-406. DOI: 10.1068/d140395.

May T (1997) Reconsidering Difference: Nancy, Derrida, Levinas, Deleuze. University Park, PA: Pennsylvania State UP.

May T (2005) Gilles Deleuze: An Introduction. New York: Cambridge University Press.

Norrie A (2009) Dialectic and Difference: Dialectical Critical Realism and the Grounds of Justice. London: Routledge.

Roffe J (2010) Multiplicities. In: Parr A (ed.) The Deleuze Dictionary Revised Edition. 2nd Revised edition. Edinburgh: Edinburgh UP, pp. 181-2.

Rutzou T (2017) Finding Bhaskar in All the Wrong Places? Causation, Process, and Structure in Bhaskar and Deleuze. Journal for the Theory of Social Behaviour. DOI: https://doi.org/10.1111/jtsb.12138. 
Searle JR (1995) The Construction of Social Reality. London: Allen Lane.

Sewell WH Jr (1992) A Theory of Structure. American Journal of Sociology 98(1): 129.

Steinmetz G (2004) Odious Comparisons: Incommensurability, the Case Study, and

"Small N's" in Sociology. Sociological Theory 22(3): 371-400. DOI:

10.1111/j.0735-2751.2004.00225.x.

\section{Notes}

i The word structure is used in many different ways. For us, objects are structures in one sense of the term, and have structure in another, and so the word can be used in both senses when discussing social structure (see Elder-Vass, 2010: 76-86). There is also a difference between what we might call actual structures and real-but-not-actual structures (see below).

ii We thank one of the reviewers for pointing out this connection.

iii We thank one of our reviewers for suggesting this line of development.

iv For a similar critical realist account of emergent properties see (Elder-Vass, 2010: 16-24).

v DeLanda argues that this is broadly consistent with D\&G, who write that "the opposition between strata and assemblages is 'entirely relative'" (DeLanda, 2016: 123; the internal quote is from Deleuze and Guattari, 1988: 392).

vi The concepts of territorialization, deterritorialization and coding are themselves highly unstable assemblages in D\&G's work. Rather than engage in a complicated and potentially controversial exegesis of their usage, we rely here on DeLanda's reading of these concepts, as this reading is embedded in the account of parameters with which we are engaging.

vii One might argue that the concept of strata implies that assemblages fall into types, and indeed D\&G briefly acknowledge that abstract machines fall into types (Deleuze and Guattari, 1988: 596).

viii Causal types must be distinguished from the Weberian notion of ideal types. An ideal type is a notional pure case of a phenomenon, often an extreme case that is never actually instantiated, such as Weber's example of charismatic authority. Actual charismatic leaders may rely on some element of tradition or rationalised rules in addition to their personality and 
achievements, but the ideal type is a notional case in which they do not. By contrast, real causal types are classes of phenomena, which many actual cases may fall into.

${ }^{i x}$ What Bhaskar calls transfactuality (Bhaskar 1975)

${ }^{x}$ The distinction between conjunctural assemblages and the other forms is also potentially fuzzy, but less significant for the argument of this paper.

${ }^{x i}$ In philosophical terms, our loose types are real kinds rather than nominal kinds: "a type of entity, all cases of which have a similar micro-structure that gives them a specific property, power, or set of such properties and powers" (Elder-Vass, 2012: 126). Note the use of "a similar" here rather than "the same". The terms we use to refer to these types, such as bureaucracy, bird, bicycle and football club, represent nominal categories, which may or may not correspond to real kinds. For further discussion of the issues this raises, see (Elder-Vass, 2012: 121-31).

xii And Bhaskar's somewhat similar transformational model of social activity (TMSA) (Bhaskar 1979).

xiii We use the term stock to refer to the institution and shares to refer to individual holdings in a company.

\section{Tables}

\begin{tabular}{|l|l|l|l|}
\hline Type & Definition & Theorized by & Examples \\
\hline Conjunctural & unique & Latour, critical & The causes of the \\
& $\begin{array}{l}\text { fonfigurations of } \\
\text { together to }\end{array}$ & realism & FrenchRevolution \\
& $\begin{array}{l}\text { produce a given } \\
\text { event }\end{array}$ & & \\
Assemblage & transient and & D\&G & \\
\hline Ephemeral & unstable wholes & & Clouds, protests \\
\hline
\end{tabular}




\begin{tabular}{|l|l|l|l|}
\hline Persistent & relatively stable & DeLanda, critical & Atoms, bicycles, \\
Assemblages & wholes that may & realism, Harman & bureaucracies \\
& have a tendency to & & \\
recur in similar & & \\
& forms & & \\
\hline
\end{tabular}

Table 1: Types of assemblages and where to find them

\begin{tabular}{|c|c|c|c|c|}
\hline Ontology & $\begin{array}{l}\text { Conjunctural } \\
\text { stability }\end{array}$ & $\begin{array}{l}\text { Structural } \\
\text { stability }\end{array}$ & $\begin{array}{l}\text { Conjunctural } \\
\text { fluidity }\end{array}$ & $\begin{array}{l}\text { Structural } \\
\text { fluidity }\end{array}$ \\
\hline $\begin{array}{l}\text { Critical } \\
\text { realism }\end{array}$ & $\begin{array}{l}\text { "closed } \\
\text { systems" - a } \\
\text { partial and } \\
\text { temporary } \\
\text { achievement in } \\
\text { experimental } \\
\text { science }\end{array}$ & $\begin{array}{l}\text { Entities falling } \\
\text { into types with } \\
\text { real causal } \\
\text { powers; system } \\
\text { reproduction } \\
\text { under the } \\
\text { influence of } \\
\text { morphostatic } \\
\text { mechanisms }\end{array}$ & $\begin{array}{l}\text { Highly } \\
\text { contingent } \\
\text { actual } \\
\text { causation in } \\
\text { open systems } \\
\text { as the norm }\end{array}$ & $\begin{array}{l}\text { Transformation } \\
\text { of entities } \\
\text { under the } \\
\text { influence of } \\
\text { morphogenetic } \\
\text { mechanisms }\end{array}$ \\
\hline Deleuze & Strata & $\begin{array}{l}\text { Strata, abstract } \\
\text { machines }\end{array}$ & $\begin{array}{l}\text { More or less } \\
\text { ubiquitous }\end{array}$ & Assemblages \\
\hline
\end{tabular}




\begin{tabular}{|l|l|l|l|l|}
\hline DeLanda & $?$ & Assemblages & More or less & Assemblages \\
& & with high values & ubiquitous & with low values \\
& & of coding \&/or & & of coding \&/or \\
& territorialization & & territorialization \\
& parameters & & parameters \\
\hline
\end{tabular}

Table 2: Fluidity and stability in three ontologies

\begin{tabular}{|l|l|l|l|l|}
\hline Case & Conjunctural & Structural & Conjunctural & Structural \\
& stability & stability & fluidity & fluidity \\
\hline MacKenzie & stock trading as & New York & Financial & Early years of \\
& an institution & Stock & technology & ATD \\
& & Exchange & & \\
\hline
\end{tabular}

Table 3: Fluidity and stability in an empirical case 